\title{
INTERFACE ENTRE FILOSOFIA E PEDAGOGIA FREIRIANA: CONTRIBUIÇÕES PARA UMA FORMAÇÃO HUMANA INTEGRAL
}

\author{
Maria Lionilde Araújo da Silva*; Josina Maria Pontes Ribeiro; Ricardo dos Santos Pereira. \\ E-mail*:lia.wilde@hotmail.com \\ Instituto Federal de Educação, Ciência e Tecnologia do Acre
}

DOI: $10.15628 /$ rbept.2020.9897

Artigo submetido em: Maio/2020 e aceito em: Set/2020

\begin{abstract}
RESUMO
O artigo apresenta reflexões sobre a importância do ensino de filosofia para a formação humana integral, considerando as necessidades dos discentes regerem suas existências históricas e políticas, de forma consciente e crítica. Como caminho teórico-metodológico escolhemos o materialismo histórico-dialético. Trata-se de uma pesquisa bibliográfica, a partir da qual contextualizamos a escola como parte de um projeto iluminista, que se consolida através de uma perspectiva pedagógica tradicional e tecnicista. Como proposta contra hegemônica a esse tipo de educação, apontamos a perspectiva sociocultural freiriana, como possibilidade para a formação omnilateral dos sujeitos do processo educativo. Ademais, na estreita relação entre filos ofia e educação, evidenciamos a pedagogia freiriana como referência para uma formação integral, tendo o diálogo como um ponto central para um ensino emancipatório.
\end{abstract}

Palavras-chave: Educação. Filosofia. Formação Integral. Pedagogia Freiriana. Diálogo.

\section{INTERFACE BETWEEN FREIRIAN PHILOSOPHY AND PEDAGOGY: CONTRIBUTIONS TO AN INTEGRAL HUMAN FORMATION}

\begin{abstract}
the article presents reflections on the importance of philosophy teaching for integral human formation, considering the student's needs to rule their historical and political existences, in a conscious and political way. As a theoretical and methodological path, we choose the historical and dialectical materialism. This is a bibliographic search, from which we contextualize the school as part of an illuminist project, that's consolidated through a traditional and technicist pedagogical perspective. As a counter-hegemonic proposal to this type of education, we point out the freirian sociocultural perspective, as a possibility for the omnilateral formation of the educational process subjects. Futhermore, in the close relationship between philosophy and education, we highlight freirian pedagogy as a reference for integral formation, using dialog as a central point for emancipatory teaching.
\end{abstract}


Keywords: Education. Philosophy. Integral formation. Freirian pedagogy. Dialog.

\section{INTRODUÇÃO}

O conhecimento intelectual e propedêutico sempre foi reservado a uma elite, da qual pertenciam filósofos, políticos, sábios e religiosos. No Brasil, com o dualismo de classes sociais e uma herança de séculos de escravismo, acentuou-se a prática de uma educação geral para as classes dominantes e uma educação técnico-profissional para a classe trabalhadora e sua prole (CIAVATTA, 2005). Porém, a proposta de formação integral, apresentada a partir da criação da Rede Federal de Educação Profissional e Tecnológica, em 2008, vem questionar a concepção de uma educação fragmentada e meramente técnica na formação dos trabalhadores brasileiros. Desse modo, nesse artigo nos propusemos a refletir sobre as contribuições do ensino de filosofia para a formação humana integral, considerando a necessidades dos alunos regerem suas existências históricas e políticas e, portanto, de uma educação emancipadora.

Nesse sentido, a filosofia é entendida como uma área do conhecimento humano que visa a emancipação e dispõe de um arcabouço teórico e prático capaz de levar o estudante a reflexões ético-políticas que podem contribuir em sua relação com o mundo em suas dimensões integradas. Logo, acreditamos em um ensino filosófico que foge da ideia de uma coleção de conteúdos da cultura erudita, pois este modelo nega as possibilidades de indagação ou intervenção da realidade.

Considerando o caminho do pensamento que determinado tema requer, toda a discussão sobre ensino de filosofia aqui proposta está teoricamente fundamentada em uma concepção sociocultural (MIZUKAMI, 2001) ou histórico-crítica (SAVIANI, 2011) de educação, tendo o materialismo histórico como caminho teórico. Como estratégia metodológica adotamos a dialética, pelo fato dela considerar as especificidades históricas da vida humana, o princípio da totalidade da existência humana e, ainda, pelo princípio da união dos contrários nela evidenciados (MINAYO, 2010, p. 111-122). Vale destacar, ainda, que a dialética é a perspectiva crítica que se propõe ao conhecimento da essência dos fenômenos e busca a sistematização de como chegar a essa apreensão do concreto, da coisa ou do fenômeno em si (KOSIK, 2002).

Para situar o ensino de filosofia a partir da abordagem sociocultural, realizamos uma revisão da literatura, evidenciando as semelhanças entre a filosofia como saber historicamente construído e a pedagogia freiriana. Assim, o trabalho está estruturado em três partes, constando a primeira de um exame teórico das principais concepções de educação, com destaque para a 
abordagem sociocultural da pedagogia freiriana. Em um segundo momento, refletimos sobre filosofia e educação, favorecendo aproximações entre a pedagogia freiriana e a tradição socrática-platônica centrada no diálogo, para estabelecimento de uma relação dialética do saber entre os indivíduos. Por fim, refletimos sobre educação profissional e tecnológica, a partir de uma perspectiva de educação humana integral, com vistas a superação da dicotomia entre formação geral e formação técnica e profissional. Nestes termos, a filosofia é compreendida como saber antiguíssimo, instrumento de reflexão e ação no mundo, de forma a contribuir com a educação para a autonomia.

\section{A EDUCAÇÃO COMO PROJETO ILUMINISTA E A POSSIBILIDADE CONTRA-HEGEMÔNICA DA EDUCAÇÃO DIALÓGICA FREIRIANA}

Para Saviani (2011, p. 11-12), a educação é um fenômeno próprio dos seres humanos e a compreensão de sua natureza perpassa pela compreensão da natureza humana. Sua natureza está diretamente ligada a ideias, conceitos, valores, símbolos, atitudes, habilidades, ou seja, uma produção de saber tanto do mundo natural quanto do cultural, totalizando o conjunto da produção humana. Sendo assim, a educação não se restringe à escolar, o processo de educação dos sujeitos se dá em ambientes formais e não-formais. Freire (2018, p.82) corrobora essa ideia ao afirmar que nenhuma ação educativa pode prescindir de uma reflexão sobre a natureza humana e uma análise de suas condições culturais, pois não há educação fora das sociedades humanas e não existem homens isolados.

A educação é, portanto, uma realidade intrínseca das sociedades humanas e sua origem confunde-se com a própria origem do homem, seja nas sociedades ditas primitivas em uma educação para a vida, seja como saber sistematizado e específico que remonta a Paideia grega, cujo ideal, fundado na educação pelo logos, remete a formação geral, a dimensão corporal, emocional, ética, política, que constituía o homem como o todo, como cidadão da polis (JAEGER, 1995, 147).

A educação remete, ainda, a instituições educacionais e políticas romanas, pelas diversas escolas do período escolástico e chega aos tempos modernos, quando se associa fortemente à pedagogia. Por sua vez, a pedagogia se constituiu numa riquíssima tradição teórica científica sobre a prática educativa, tendo, de um lado, um sentido de reflexão estreitamente ligado a filosofia, elaborada de forma teleológica (ethos educativo) e, de outro lado, a pedagogia é pensada de forma mais empírica, inerente a formação na 
paideia, como caminho no sentido metodológico, o que podemos entender como "condução da criança" (SAVIANI, 2008, p. 1-2).

Os filósofos clássicos eram grandes educadores e, com a influência do pensamento da antiguidade clássica no desenvolvimento histórico-cultural da filosofia ocidental, a relação filosofia e educação foi se estreitando cada vez mais. A filosofia escolástica foi, literalmente, o suporte fundamental de um método pedagógico responsável pela formação cultural e religiosa das gerações europeias, construídas sobre os escombros da cultura greco-romana. O Renascimento, com seu projeto humanista de cultura baseada na tradição grega e no lluminismo, e seu projeto da razão para estruturação da civilização ocidental moderna, também convergiu para aproximação entre filosofia e educação (SEVERINO, 1990, p. 2-3).

No lluminismo se resgatou uma ideia platônica de educação moral e intelectual como papel do Estado, sendo a escola uma instituição de projeção de valores que seriam transmitidos para formar o espírito esclarecido do homem em prol do exercício da cidadania. Tal princípio fundaria a ideia de estado iluminista, engajado com o interesse da classe burguesa para a construção do que se chamaria de processo de civilização homogênea, progressista e unificada. A civilização constitui-se, portanto, numa ampla perspectiva cultural capaz de homogeneizar as diferenças mais profundas entre os povos e de impor um padrão único e universal ao modo da nação ou povo. Conforme o ideal iluminista, as manifestações culturais regionais necessitam ser suplantadas por um processo de instrução capaz de levar os povos a se organizarem e agirem conforme a universalidade da natureza humana, à racionalidade e às conquistas das ciências e da técnica (SILVA, 2007; 2010).

Para essa instrução universal, que seria a principal bandeira da burguesia em ascensão em sua busca de difundir sua ideologia, a escola era entendida como imprescindível meio de socialização e instrumentalização do saber científico. Nesse sentindo, podemos afirmar que a nossa concepção de escola, como instituição pedagógica responsável pela "socialização do saber sistematizado", como uma "circunstância privilegiada", ainda remonta ao século das luzes, como fica evidente na afirmação de Saviani (2011, p. 13-14), segundo o qual:

[...] a escola tem a ver com o problema da ciência. Com efeito, ciência é exatamente, o saber metódico, sistematizado. A esse respeito, é ilustrativo o modo como os gregos consideravam essa questão. Em grego temos, três palavras referentes ao fenômeno do conhecimento: doxa, sofia e episteme. Doxa significa opinião, isto é, o saber próprio do senso comum, o conhecimento espontâneo ligado diretamente à experiência cotidiana, um claro-escuro, misto de 
verdade e de erro. Sofia é a sabedoria fundada numa longa experiência [...]. E finalmente episteme, significa ciência, isto é, conhecimento metódico e sistematizado [...]. É a exigência de apropriação do conhecimento sistematizado por parte das novas gerações que torna necessária a existência da escola. A escola existe, pois para apropriar a aquisição dos instrumentos que possibilitam o acesso ao saber elaborado (ciência), bem como o próprio acesso ao rudimento desse saber.

Gaddoti (1991, p. 21) assevera que a burguesia foi feliz e eficaz ao disseminar sua ideologia através da escola até que, em meados do século $X X$, tal classe gradualmente deslocou sua maior atenção para veículos de comunicação de massa, que se mostravam mais poderosos e rápidos na disseminação das suas ideias, acompanhando, assim, a aceleração dos processos econômicos, sociais e políticos característicos da época neoliberal que a sociedade adentrava.

Rodrigo (2007, p. 37-41) analisa as influências econômicas e mudanças sociais pelas quais a escola passou na década de 1970, no mundo e no Brasil, ao passar por uma massificação do ensino médio, recebendo estratos sociais menos privilegiados e anteriormente excluídos.

O segmento social que chegava à escola secundária possuía carências culturais e problemas educativos de várias ordens e a pedagogia tradicional, predominante na escola, foi idealizada para acolher uma clientela social mais exclusiva, tornando-se inadequada a esse novo cenário. O que chamamos de pedagogia tradicional, portanto, é um conjunto de enunciados filosóficos referidos à educação, a partir de uma visão essencialista dos seres humanos, fundamentada em um inatismo, que naturaliza o fracasso escolar e transfere à educação uma tarefa de conformar o indivíduo para a perpetuação de uma desigualdade de classes (SAVIANI, 2008, p.68).

Já a pedagogia tecnicista apresenta-se como uma proposta educacional mais concatenada e cristalizada nos ideais econômicos da década de 1970, que se coloca como ramo científico balizado no ideal behavorista, ao buscar explicar o fenômeno educativo a partir de descrições empíricas, visando a concretude de enunciados operacionais suscetíveis de orientar universalmente uma prática educativa (SAVIANI, 2008, p.69).

Contrapondo essas pedagogias, colocam-se as pedagogias libertárias, dentre elas a pedagogia histórico-crítica e a pedagogia freiriana, importantes como possibilidades para um processo educativo dialético e comprometido com a mudança social e emancipação dos indivíduos. Saviani (2011, p. 75-76) elucida a nomenclatura de sua pedagogia, nos ensinando que a pedagogia histórico-crítica pode ser sinônimo de uma pedagogia dialética. No entanto, a partir da década de 1980, devido a generalizações e diversas interpretações 
acerca da dialética, o autor cunhou o termo pelo qual sua pedagogia é atualmente conhecida. Assim, entendemos a pedagogia histórico-crítica como o empenho em compreender a questão educacional pela dialética da história, utilizando como pressuposto teórico o materialismo histórico, ou seja, a compreensão da história a partir da determinação das condições materiais da existência humana.

Já seguindo essa linha contra hegemônica, Saviani (1999, p. 79-83) afirma que o ensino é o processo pelo qual o professor estimula atividades, iniciativas e criatividade dos alunos. Trata-se do momento em que alunos e professor dialogam a partir da cultura historicamente acumulada pela humanidade. Para que esse processo seja ativo, o educador deve levar em consideração o interesse, os diferentes ritmos de aprendizagem e 0 desenvolvimento psicológico do aluno, mas, sem perder de vista a sistematização lógica do conhecimento, assim como também sua ordenação no processo de construção cognitiva do educando. O ensino preconiza, portanto, o vínculo entre educação e sociedade, tomando professor e aluno como agentes sociais. Desse modo, o ensino não é uma linha reta ou estados positivistas de desenvolvimento, no qual o aluno irá acumulando informações e dados culturais, mas um ciclo que tem que começar da prática social dos envolvidos nas situações de aprendizagem, perpassar diversos estágios (problematização, instrumentalização, catarse) de apropriação e, ainda, ter como ponto de chegada novamente a prática social, agora acrescida de uma alteração qualitativa, o que consiste na apropriação do saber histórico para transformar o meio social.

Freire (2018, p. 24-26) afirma que ensinar não é transferir ou depositar conhecimento, mas criar possibilidades para sua construção e sua produção. "Quem ensina aprende ao ensinar e quem aprende ensina ao aprender [...]". Nessa perspectiva, ensinar inexiste sem aprender e foi aprendendo socialmente que a humanidade entendeu que é possível ensinar. Para Saviani (2008, p. 100-101) a pedagogia libertadora de Paulo Freire se evidencia no Brasil, na década de 1960, e é uma das pedagogias mais emblemáticas do progressismo educacional. Freire suscita um método pedagógico que tem como ponto de partida a vivência popular, de modo que identifique seus problemas e se operem escolhas de temas geradores, cuja problematização levaria à conscientização e que, por sua vez, culminaria em ação política e social.

Mizukami (2001) denomina a pedagogia freiriana como abordagem sociocultural que considera o processo educativo como subjetivo, histórico e multidimensional, a partir do qual se encontram dimensões humanas, técnicas, cognitivas, emocionais, políticas e culturais. Logo, a abordagem que utilizaremos e na qual se baseia nossa concepção pedagógica de educação é 
a abordagem sociocultural, cujo principal representante na educação brasileira é Paulo Freire.

Ao tratar da relação "homem e mundo" em Freire, Mizukami (2001, p.86) coloca-os em uma relação direta, o que é característica de uma abordagem interacionista. É certo que na abordagem freiriana existem "apenas homens concretos, situados no tempo e no espaço, inseridos em um contexto sócioeconômico-cultural-político". Sendo assim, a educação deve levar em conta a "vocação ontológica" do homem, as condições em que ele vive, uma vez que o homem se efetivará como sujeito através da reflexão sobre seu ambiente concreto. Quanto mais ele avança nessa reflexão, mais consciência ele tem de si, enquanto ser da práxis, capaz de intervir na realidade em que vive para transformá-la. Ademais, para a autora, a pedagogia de Freire é baseada na "palavra" e fundada em uma visão ética da realidade a respeito do ser humano e de sua autonomia. Nesse contexto, os indivíduos tomam consciência de sua condição, através de uma relação dialógica, o que leva a transformação e mudanças na realidade em que estão inseridos.

Para Freire (2018, p.108), a educação é política, não no sentido de política partidária, mas, no sentido da política enquanto construção grega de polis, como forma de exercer um poder em uma comunidade. A raiz mais profunda da politicidade da educação se encontra na educabilidade dos seres humanos que se funda em sua natureza inacabada, histórica e ética.

Ghiraldelli Jr. (2000, p. 50) aproxima Freire e Dewey ao demonstrar que os dois veem a educação como uma ação política e ativa. Porém, Freire construiu uma abordagem não nos moldes ao Welfare State Keynesiano. Por isso, o pensamento de Freire é uma crítica à face desumanizadora do industrialismo perverso do mundo do trabalho. Simon (2014, p. 1.356) também faz uma diferenciação dos supracitados autores ao afirmar que a pedagogia de Dewey é o ápice de uma série de pedagogias do iluminismo, em que se educa para a liberdade e para formar cidadãos competentes e ativos na sociedade, porém sem chegar a um questionamento das estruturas das classes sociais. É certo que, a partir da Pedagogia do Oprimido, ainda na década de 1960, Freire rompe visivelmente com o iluminismo e passa a entender que a educação, mais que uma ação para liberdade, deve assumir uma práxis para a libertação do indivíduo das opressões econômicas, tal como segue:

Se a educação não pode tudo, alguma coisa fundamental a educação pode. Se a educação não é chave das transformações sociais, não é também simplesmente reprodutora da ideologia dominante. O que quero dizer é que a educação nem é uma força imbatível a serviço da transformação da sociedade, porque assim eu queira, nem tampouco 
é a perpetuação do status quo, porque o dominante decrete. 0 educador e educadora crítico não podem pensar que, a partir do curso que coordenam ou do seminário que lideram, podem transformar o país. Mas podem demonstrar que é possível mudar (FREIRE, 2018, p. 110).

A pedagogia de Freire (2019, p. 34-36) é baseada na "palavra" e fundada sobre uma visão ética e humanista da realidade do ser humano e de sua autonomia. Tal pensamento reflete a necessidade educacional de se entender a existência humana a partir de sua historicidade, ou seja, pensar o ser humano como sujeitos históricos construídos.

Em Freire (2018, p. 141), o diálogo "como encontro dos homens para a pronúncia do mundo" também assume papel fundamental na constituição da consciência, pois essa é dialógica com os homens e o mundo, "é a própria consciência histórica".

Na educação dialógica, a consciência se transforma em conscientização quando homens e mulheres através da palavra entram em comunhão entre si e com o mundo. "Conscientização, é óbvio, que não para, estoicamente, no reconhecimento puro, de caráter subjetivo, da situação, mas pelo contrário, que prepara os homens, no plano da ação, para a luta contra os obstáculos à sua humanização" (FREIRE, 2018, p.158).

Freire entende, portanto, que os homens se constroem dialética e dialogicamente com o mundo. A abertura ativa e militante com as diversas realidades pode garantir o caráter dialógico da educação para viver, conviver e humanizar-se com os outros. Por isso, o diálogo é a alavanca para o processo educativo dos homens comprometidos com o mundo e sua mudança. Essa característica da pedagogia freiriana retoma a dialética em suas origens gregas e nos apresenta a situação diretamente relacional entre diálogo e dialética como elemento central da Filosofia, principalmente na sua amplitude política enquanto paideia.

\section{FILOSOFIA E EDUCAÇÃO: A PALAVRA COMO ELEMENTO DE APROXIMAÇÃO ENTRE A TRADIÇÃO DIALÓGICA GREGA E A PEDAGOGIA FREIRIANA}

Alexandre Dumas foi um dos maiores romancistas da literatura universal, seus livros e seus personagens estão no imaginário cultural da humanidade. Um de seus mais famosos personagens é Edmund Dandès, jovem que se torna o Conde de Monte Cristo para vingar-se de pessoas que 0 levaram à prisão. Dandès, um marinheiro analfabeto, encontrou o Abade Faria 
no cárcere e com ele começou um processo educativo, contemplando em apenas três anos os princípios de todas as ciências da época para dar início a sua vingança. $O$ rapaz questiona se em tão pouco tempo conseguirá dominar as letras eruditas tão longe de sua realidade de trabalhador. $O$ abade responde: "Em sua aplicação, não. Em seus princípios, sim. Aprender não é saber. Há sabidos e sábios. A memória faz os primeiros. A filosofia que faz os outros [...] A filosofia é uma reunião das ciências adquiridas pelo gênio que as aplica" (DUMAS, 2014, p. 67).

A concepção de filosofia do personagem Faria é uma filosofia da aplicabilidade, uma filosofia da práxis e, ainda em uma cela, Edmund Dandès inicia seu processo de libertação e punição de seus algozes. Isso se realiza através da educação e da filosofia apreendida com seu companheiro de cela que lhe dá uma percepção de toda a conspiração que o fez perder a liberdade. Nesse momento, o jovem começa a transformar a sua realidade e de todos os envolvidos no romance.

Mas, o que um romance de ficção como o Conde de Monte Cristo tem a nos dizer sobre a filosofia e educação como libertação? Ora, Italo Calvino (2007, p.11) conceitua que "um clássico é um livro que nunca terminou de dizer aquilo que tinha para dizer". O Conde de Monte Cristo é um livro sobre um aspecto da natureza humana. O que podemos aprender com o personagem de Dumas é que a filosofia pode dar subsídios para a libertação dos indivíduos, para que enxerguem suas situações concretas e lutem para a superação, tal qual nos diz Paulo Freire e sua filosofia da educação de finalidade libertadora.

O entendimento da educação como ato político é comum à filosofia desde sua gênese grega, a que se atribui o início da atitude filosófica, como resultado da perplexidade, do espanto, da maravilha. Destarte, a maravilha se constitui como característica primordial do homem que se defronta com uma realidade que ele não consegue compreender de imediato, sendo tal característica comum a todos os seres humanos (ARISTOTELES, 1982; GILES, 2007).

Atribuímos aos gregos o início da atitude filosófica. A expansão urbana da sociedade grega, o florescimento do comércio, a democracia ateniense, bem como a necessidade do desenvolvimento da alfabetização grega para a promulgação das leis da polis, fizeram com que os homens livres dedicassem um tempo para investigar as questões de origem política, de natureza cosmológica e educacional (LUCE, 1994, p 17).

Durante toda sua história, a filosofia ocupou-se não apenas com os questionamentos, mas também com a busca do saber e de sua valorização. Desde o seu nascimento na pequena cidade de Mileto no século VI a.C, a atividade filosófica esteve diretamente ligada a seu ensino. Diversos filósofos e escolas filosóficas desenvolveram não só o conhecimento erudito e formal da 
época, mas também construíram métodos e concepções de ensino, sejam as mais informais como era a maiêutica e ironia socrática, seja como os diálogos platônicos produzidos para a realidade exterior à Academia, ou como o método peripatético de ensinar filosofia caminhando em contato com a natureza e desenvolvendo os sentidos para o mundo concreto.

A ágora grega foi o espaço público e aberto em que a filosofia se desenvolveu para explicar a realidade concreta, não mais através do discurso mítico e poético, mas para explicá-la através do logos (palavra), enquanto discurso racional.

Pensar a filosofia hoje para ser paideia é fazer uma filosofia para formar o cidadão para a realidade em todas as suas dimensões e habilitá-lo como crítico em sua realidade política e decodificadora do mundo contemporâneo (SEVERINO, 2007).

Seguindo a tradição socrático-platônica, filosofar é entrar em diálogo através do perguntar e responder e em interação com os outros. Sendo assim, o diálogo é tomar consciência de si, através do encontro com o outro, como caminho filosófico de autocompreensão para os seres humanos em devir, no sentido de experiência ética, política e estética de sua existência na totalidade.

A filosofia que vai do saber ao não-saber, ainda hoje não pretende oferecer soluções prontas, isentas de questionamentos e problemáticas. Aliás, o ato de filosofar não deve se limitar a uma simples contemplação ou constatação dos fatos, mas precisa ser uma problematização com engajamento, pois a filosofia é "[...] uma das poucas atividades que podem sacudir a realidade nos seus alicerces mais profundos, inclusive o eu que filosofa" (GILES, 2007, p. 5).

Por isso, a filosofia afirma-se historicamente como saber necessário para estabelecer reflexões sistemáticas e rigorosas sobre todas as áreas de conhecimento, nos mais diversos graus de complexidade e nas mais diversas realidades ético-políticas. Saviani e Duarte $(2015$, p. 15) vão corroborar a ideia ao aproximar filosofia e educação, afirmando que "[...] a filosofia é a forma mais elaborada, do grau mais elevado, de compreensão do homem atingido pelo próprio homem". Mas, esse grau elevado só pode ser alcançado por homens de "alma elevada e espirito cultivado"? A resposta é não. Se a compreensão da filosofia jazer limitada aos ciclos acadêmicos autorizados, qual será a serventia para os não acadêmicos conhecerem ou não conhecerem conteúdos fragmentados de fatos filosóficos da história da filosofia?

Acreditamos, portanto, em uma filosofia como atividade filosofante. Para isso, resgatamos a máxima aristotélica onde os seres humanos tendem ao saber, ao espanto filosófico com o desconhecido. Gramsci (1986, p. 11) afirma que "todos os homens são filósofos", contrariando o pensamento de filosofia 
como algo inacessível e direcionado a um seleto grupo de iniciados, que retiraria qualquer possibilidade para o homem trabalhador comum e sua prole acessarem o pensamento dos filósofos e da história da filosofia. Essa intimidação e preconceito são, em grande parte, de caráter político, pois o contato da massa com a filosofia elevaria seu patamar cultural, seu nível de compreensão do mundo social e aumentaria suas chances de intervenção na realidade social, permitindo a superação do senso comum para um estado de criticidade. Assim, uma parte da sociedade mais abastada deseja que as massas continuem exatamente onde se encontram. Gramsci (1986, p. 11) nos chama atenção afirmando que:

[...] é preciso destruir o preconceito, muito difundido, de que a filosofia seja algo muito difícil pelo fato de ser uma atividade intelectual própria de uma determinada categoria de cientistas especialista ou filósofos profissionais e sistemáticos. Deve-se, portanto, demonstrar, preliminarmente, que todos os homens são filósofos.

Nesses mesmos termos, ainda Gramsci (1976, p. 82) nos alerta do perigo de conceber o conhecimento cultural como enciclopedismo e mera transmissão de ideias. Segundo o autor:

É preciso perder o hábito e deixar de conceber a cultura como algo enciclopédico, no qual o homem é visto sob a forma de recipiente para encher e amontoar com dado, com fatos ao acaso desconexos, que ele depois deverá arrumar no cérebro como nas colunas de um dicionário para poder então, em qualquer altura, responder aos vários estímulos do mundo externo. Esta forma de cultura é deverás prejudicial, especialmente ao proletariado. Serve apenas para criar desajustados, ente que crê ser superior ao resto da humanidade porque armazenou na memória certa quantidade de dados e datas, que aproveita todas as ocasiões para estabelecer quase uma barreira entre si e os outros.

A filosofia é por vezes árida e rigorosa e nem sempre o seu estudo é prazeroso ou divertido, mas desestimular os indivíduos de que a filosofia é um saber inacessível a determinados segmentos sociais e educacionais é perpetuar uma ideologia da classe dominante. O próprio Aristóteles (1982, p.45), em Metafísica I, afirma que:

[...] todos os homens tendem por natureza ao saber: sinal disto é o prazer produzido neles pelas sensações, já que estas, independentemente da sua utilidade, são amadas por si mesmas, e, 
mais do que todos, aquela que é produzida pelo olhar. Pode-se dizer, de fato, que preferimos a visão a todas as outras sensações, não só quando temos um objetivo prático, mas também quando não pretendemos realizar qualquer ação. E o motivo é que essa sensação, mais do que qualquer outra, nos permite adquirir conhecimento e nos revela de imediato uma grande quantidade de diferença. Assim como no início, os homens até hoje encontram no assombro o motivo para filosofar, porque antigamente eles se maravilhavam diante dos fenômenos mais simples, dos quais não podiam dar-se conta, e depois, paulatinamente, se encontravam diante de problemas mais complexos, como as condições da Lua e do Sol, e as estrelas, e a origem do universo.

Em suma, essa obrigação nasce da maravilha, se desenvolve pelo logos (palavra) e firma-se na formação ético-política dos cidadãos, considerando que a finalidade da natureza humana é ser parte de uma comunidade política (ARISTOTELES, 1997, p. 14).

Deleuze $(2017$, p. 39) também corrobora a ideia de que a filosofia não é reservada apenas a professores de filosofia ou alguns filósofos profissionais, se torna filósofo quem se interessa por esse saber conceitual. Saviani (1990) vai além, ao afirmar que os assuntos de que se ocupa a filosofia são de interesse de todos os homens, já que todos os homens pensam.

A filosofia é, portanto, aqui entendida como atitude reflexiva (ASPIS, 2014; GALLO, 2012) e "arte de criar conceitos" (DELEUZE, 2016) destinados a elucidar os problemas com que o homem se defronta no transcurso de sua existência. Por isso, para Saviani (1990, p. 6-7) a filosofia - entendida como concepção de mundo que expressa de forma elaborada, logicamente consistente e coerente - formula e encaminha a solução dos grandes problemas postos pela época que ela se constitui. Como tal, ela contém em si, de forma sintética e conceitual, a problemática da época. Por isso, os filósofos que a História reconhece como tais, são os grandes intelectuais que conseguiram expressar de forma mais elaborada os problemas das respectivas fases de desenvolvimento da humanidade. Nesse sentido, se tornaram clássicos, já que suas formulações extrapolam os limites de uma determinada época, mantendo o seu interesse mesmo para ulteriores períodos.

No sentido referido, o estudo crítico da filosofia, isto é, dos clássicos da filosofia, é uma via de acesso à compreensão da problemática humana, o que tem grande valor educativo, já que a educação não é outra coisa senão o processo através do qual se constitui em cada indivíduo a universalidade própria da espécie humana. Com efeito, as filosofias, refletem os problemas e contradições de sua época. Em consequência, o estudo crítico irá reconhecer os conflitos e as lutas entre diferentes concepções filosóficas no interior de uma 
época e ao longo do desenvolvimento da história da humanidade (SAVIANI, 1990).

$\mathrm{O}$ ato de filosofar é um processo de construção que concretiza e, ao mesmo tempo, impulsiona um projeto de homens e mulheres em formação. Esse processo não pode se limitar a simplesmente constatar uma realidade, mas deve levar à compreensão e à disposição de transformar essa mesma realidade graças à liberdade criativa por ele ativada (GILES, 2007, p. 28).

Por isso entendemos que a filosofia, em suas diversas dimensões, pode contribuir com a tarefa de educar o indivíduo de tal forma que esse ato ultrapasse os limites de formação apenas profissional para estender-se a uma visão global da existência. Para isso, a filosofia nunca deve se distanciar da realidade concreta em que o educando se encontra, pois, o processo educativo reflete e determina a vida de homens concretos, comprometidos com a realidade e sua transformação (FREIRE, 2019, p. 34). Deste modo, concordamos com Freire quando ele defende que a formação meramente técnica, com a pretensão de ser neutra e ingênua, nega a historicidade dos homens e mulheres do conhecimento. Por isso,

Impõe-se que tenhamos uma clara e lúcida compreensão de nossa ação, que envolve uma teoria, quer o saibamos ou não. Impõe-se que, em lugar da simples "doxa" em torno da ação que desenvolvemos, alcancemos o "logos" de nossa ação. Isso é tarefa específica da reflexão filosófica. Cabe a esta reflexão incidir sobre a ação e desvelá-la em seus objetivos, em seus meios, em sua eficiência (FREIRE, 1985, p. 26-27).

Uma técnica ou a prática profissional, à luz da reflexão filosófica ganha (re)significação ao ser desvelada por uma teoria, segundo a qual o estudante deve apropriar-se lucidamente, passando de uma "doxa" para um "logos" (FREIRE, 1985, p. 28).

Mas, para tal passagem os alunos trabalhadores devem ter arcabouços teóricos e práticos que contextualizem e integrem em sua formação, as áreas técnica e geral, de forma a contribuir com uma formação politécnica ou omnilateral, que anseia formar o trabalhador em sua dimensão intelectual, produtiva e política articulada ao mundo da cultura. Tal educação, de viés profissional e tecnológico, vem sendo debatida e defendida nos últimos anos no Brasil, tanto por pensadores como por militantes da educação, o que nos leva a interpretar que essa proposta não possui apenas natureza pedagógica, mas essencialmente política. Mais do que isso, entendemos que a proposta está comprometida com a superação da dicotomia entre a formação geral e técnica, com a redução das desigualdades sociais, com o desenvolvimento socioeconômico do país e, ainda, com a promoção de uma escola pública de qualidade. 


\title{
4 A CONTRIBUIÇÃO DA ATIVIDADE FILOSÓFICA À FORMAÇÃO HUMANA INTEGRAL NA EDUCAÇÃO PROFISSIONAL
}

As $O$ tema da educação integral coloca em voga uma concepção de educação que está em disputa permanente na história da educação brasileira: educar a todos ou a uma minoria, supostamente, mais apta ao conhecimento? A uns e a outros que tipo de educação deve ser dada, de modo a atender as necessidades da sociedade? A ideia da formação integral propõe superar "[...] o ser humano dividido historicamente pela divisão social do trabalho entre a ação de executar e a ação de pensar, dirigir ou planejar". Como formação humana integral o que se anseia é garantir ao adolescente, ao jovem e ao trabalhador o direito a uma formação completa de leitura de mundo e para a atuação como cidadão pertencente ao seu país, integrado à sua sociedade política (CIAVATTA, 2005, p. 85).

Ciavatta (2005, p. 86), continua afirmando que historicamente o conhecimento sempre foi uma reserva de poder das elites, nas quais se incluíam os filósofos, os sábios, os religiosos. No Brasil, o dualismo das classes sociais, a desigualdade de acesso aos bens e serviços produzidos, se acentua no tecido social através de séculos de colonização, escravismo e discriminação do trabalho manual:

\begin{abstract}
Na educação, apenas na metade do século XX o analfabetismo se coloca como uma preocupação das elites intelectuais, a educação do povo se torna objeto de políticas de Estado. Mas sua organicidade social está em reservar a educação geral para as elites intelectuais dirigentes e destinar a preparação para o trabalho para os órfãos e desamparados. Esse dualismo toma um caráter estrutural especialmente a partir da década de 1940, quando a educação foi organizada de acordo com setores produtivos e as profissões, e separando os que deveriam ter ensino secundário e a formação propedêutica para a universidade e os que deveriam ter formação profissional para a educação (CIAVATTA, 2005, p. 87).
\end{abstract}

A origem da ideia de integração entre a formação geral e a educação profissional no Brasil estava pautada na busca de superação do tradicional dualismo da sociedade, refletida diretamente na educação brasileira, nas lutas pela democracia e em defesa da escola pública nos anos 1980, segundo Saviani (2013, p.13), pretendia a educação pretendia "[...]a superação da dicotomia entre trabalho manual e trabalho intelectual, entre instrução profissional e instrução geral".

Para uma proposta de formação integral que vislumbre compreender a realidade para além das aparências dos fenômenos, precisamos considerar toda a organização curricular a partir de dois 
pressupostos filosóficos, sendo o primeiro a concepção de homem como ser histórico e social, que age sobre a natureza para atender suas necessidades e nessa atividade produz conhecimento que transforma a natureza e a si próprio. Como segundo pressuposto filosófico, consideramos a realidade concreta como uma totalidade estruturada e dialética, síntese de múltiplas relações. Desse modo, os conceitos e teorias de ensino são vistos como sínteses da apropriação histórica da realidade material e social do homem (RAMOS, 2005, p.115).

O ideário da formação integral resgata o princípio de formação humana total em termos epistemológicos e pedagógicos que integram ciência, cultura, humanismo, filosofia e tecnologia, visando ao desenvolvimento de todas as potencialidades humanas (FRIGOTTO, 2005, p. 35-36). Para essa formação integral do ser humano, Saviani (2011) compreende que a socialização científica, filosófica e artística é direito humano por ser um processo histórico da humanidade.

Tais acepções incidiram em um entendimento de que um recurso viável para superar essa dicotomia seria um ensino médio que assegure a integralidade da educação básica, ou seja, que contemple o aprofundamento dos conhecimentos científicos, humanísticos, filosóficos e artísticos historicamente produzidos pela humanidade, como também uma formação profissional numa perspectiva de integração. Adotar a ciência, a cultura e o trabalho como eixos estruturantes é contemplar as bases em que se pode desenvolver uma educação politécnica e, ao mesmo tempo, uma formação profissional determinada pela cruel realidade econômica do Brasil. Sob uma base unitária, o ensino médio integrado ao técnico, é uma condição indispensável para se fazer a transição para uma nova realidade (BRASIL, 2007, p. 24). Para tanto, torna-se necessário que se garanta, pelo menos filosoficamente, a integralidade do ser humano defendida ferrenhamente nas bases teóricas que formam os Institutos Federais de Educação Profissional e Tecnológica.

Ora, se a formação profissional no ensino médio é uma imposição da realidade da população trabalhadora brasileira, admitir legalmente essa necessidade é um problema ético-político. Porém, na perspectiva de educação integral não se almeja apenas atender essa necessidade, mas mudar as condições em que ela se constitui (CIAVATTA, 2005, p.198).

Como uma contraproposta a uma educação fragmentada e limitante para a classe trabalhadora, a concepção de educação integrada, tendo o trabalho como princípio educativo, não é, necessariamente, profissionalizante, a profissionalização passa por ela. Essa foi a bandeira de diversos educadores que, comprometidos com uma escola includente e que possibilitasse a superação das desigualdades sociais, foram em defesa de uma escola integrada ao mundo do trabalho que propiciasse uma educação omnilateral aos seus alunos. Mas, entendemos que a educação profissional e tecnológica, sob o ideário da integralidade dos seres, é um ganho sem precedentes para a 
justiça social desse país, tendo como marco importante a criação dos Institutos Federais (FRIGOTTO et al, 2014; PACHECO, 2010).

Aliás, uma possibilidade de acesso ao ensino comprometido com a omnilateralidade para os filhos da classe trabalhadora seria o ingresso em uma das instituições que compõem a Rede Federal de Educação Profissional e Tecnológica, que, historicamente, atuam com referência em vários dos componentes que constituem a formação integral (BRASIL, 2007, p. 26). Os Institutos Federais foram criados pela Lei o 11.892 (BRASIL, 2008) e tem como foco pedagógico "não formar um profissional para o mercado, mas sim um cidadão para o mundo do trabalho - um cidadão que tanto poderia ser um técnico quanto um filósofo, um escritor ou tudo isso" (PACHECO, 2011, p. 11).

A tríade composta por ensino, pesquisa e extensão aparece como uma forma eficiente e inovadora na metodologia de ensino atual. Segundo Pacheco (2010) apenas 3\% das 2.252 instituições de ensino superior entendem a indissociabilidade entre ensino, pesquisa e extensão. Esse número cai vertiginosamente nas instituições de ensino médio, onde geralmente essa associação não se configura como parte metodológica.

Como princípio em sua proposta político-pedagógica, os Institutos Federais ofertam: a) educação básica, principalmente em cursos de ensino médio integrado à educação profissional; b) ensino técnico em geral; c) graduações tecnológicas, licenciatura e bacharelado em áreas em que a ciência e a tecnologia são componentes basilares, e d) programas de pósgraduação lato e stricto sensu.

O desenho curricular dos Institutos Federais, pautado na verticalização e transversalidade, contribui para a singularidade de sua oferta educativa. A transversalidade fala diretamente do diálogo educação e tecnologia, sendo esta última o elemento transversal presente no ensino, na pesquisa e na extensão, filosoficamente entendido como uma dimensão que extrapola os limites das simples aplicações técnicas e agrega aspectos críticos, socioeconômicos, políticos e culturais.

Portanto, uma educação integrada e um ensino integrado não poderão furtar-se da reflexão radical e crítica, e a filosofia pode oferecer os instrumentos para a construção de um pensar autônomo, condição fundamental na formação integral do sujeito, visto e percebido dentro de sua realidade social. Ramos (2005, p. 91-92) afirma que a educação profissional não consiste em puramente ensinar a fazer e preparar para o mercado, mas proporcionar a compreensão das dinâmicas sociais, políticas e econômicas das sociedades modernas, e também habilitar as pessoas para o exercício autônomo e crítico das profissões. Essa relação pretende integrar "a formação plena do educando, possibilitando construções intelectuais elevadas; a apropriação de conceitos necessários para a intervenção consciente na realidade e a compreensão do processo histórico de construção do conhecimento".

Ramos (2009) e Ciavata (2016) elucidam que para uma educação integral é necessária uma prática integrada de compreensão global do 
conhecimento. Se imaginarmos que a realidade é um todo, uma unidade integrada entendida assim desde Parmênides e Heráclito, a integração é primordial para uma formação integral da pessoa na ideação de formação politécnica e omnilateral dos trabalhadores para a constituição de seres em devir, seres com consciência de sua historicidade e papel como sujeito das relações sociais.

A filosofia, como parte unificante da cultura ocidental, carrega em si os conceitos e práticas essenciais para conhecer a realidade de forma integrada e que, pensada nos termos de uma práxis educativa, pode contribuir com o projeto da educação profissional comprometida com a formação humana integral. Ramos (2016, p. 93) propõe uma escola ativa com um princípio educativo que unifique na pedagogia as dimensões filosóficas do éthos, do logos e do técnos:

\begin{abstract}
Com isto queremos erigir uma escola ativa e criadora organicamente identificada com o dinamismo social da classe trabalhadora. Como nos diz Gramsci, essa identidade orgânica é construída a partir de um princípio educativo que unifique, na pedagogia, éthos, logos, e técnos, tanto no plano metodológico quanto no epistemológico. Isso porque esse projeto materializa, no processo de formação humana, entrelaçado entre trabalho, ciência e cultura, revelando um movimento permanente de inovação do mundo material e social.
\end{abstract}

Então, como o ensino de filosofia pode contribuir com a proposta de integração entre educação básica e a dimensão profissional dos alunos? $O$ ensino de filosofia contribui através do diálogo do homem com as coisas postas do mundo, em seu exercício, para fazer dos estudantes agentes críticos capazes de pensar por si mesmos, de não dar nada como suposto e compreender ou, quem sabe, desconstruir o mundo (CERLETTI, 2009, p.49).

Apontamos ainda que a importância da filosofia para a formação humana é essencial, na medida em que interessa não a apenas a poucos homens, mas a todos, à humanidade em seu conjunto orgânico. O conteúdo da filosofia é histórico, isto é, produção da existência humana no tempo e no espaço e por isso deve, em um âmbito de uma educação democrática, ser ensinada a todos (SAVIANI, 2013, p.15).

Partindo dessa concepção, a filosofia e seu ensino estão equipados por dois mil e setecentos anos de teorias e conceitos, aptos a problematizar as formas de pensar dos sujeitos sobre si, o que implica uma transformação, ao problematizar o éthos, o téknos e o logos das diversas sociedades e culturas. Temos que lembrar que a filosofia não é só um conjunto de doutrinas acumuladas por milênios, ela é também uma prática, que pode subsidiar o aluno do ensino médio na compreensão do lugar que ocupa dentro de sua realidade histórica. Concordamos com Freire (2018, p. 55-56) sobre o papel da ética dentro do ensino técnico: 
O mundo da cultura que se alonga em mundo da história é um mundo de liberdade, de opções, de decisões, mundo de possibilidades em que a decência pode ser negada, a liberdade, ofendida e recusada. Por isso mesmo a capacitação de mulheres e homens em torno de saberes instrumentais jamais pode prescindir a sua formação ética. A radicalidade desta exigência é tal que não deveríamos necessitar sequer insistir na formação ética do ser ao falar de sua preparação técnica e científica. É fundamental insistirmos nela precisamente porque, inacabados nos conscientes de nosso inacabamento, seres de opção, da decisão, éticos [...].

Reconhecer o mundo e nós, humanos, como seres inconclusos em eterno aperfeiçoamento é o que nos faz educáveis e funda a educação como processo permanente (FREIRE, 2018, p. 57). Por isso, pensar um ensino de filosofia em um contexto de formação integral é necessariamente pensar uma aula na qual os educandos possam manusear os conceitos filosóficos como ferramentas de explicação do mundo, denunciando o que Deleuze (1976, p. 50) chamou de baixeza das ideologias, que mantém as explorações e abismos sociais.

Cerletti $(2009$, p.124) entende que filosofia se constrói no diálogo e, portanto, não consiste em uma questão privada. Assim, ensinar significa retirar a filosofia do mundo privado exclusivo de uns poucos para colocá-la aos olhos de todos, na construção coletiva de um espaço público. Em última instância, cada um poderá escolher se filosofa ou não, mas deve saber que pode fazêlo, que não é um mistério insondável, para uma casta de eleitos que a atesouram e a colocam num antiquário de ideias.

Precisamos de um ensino de filosofia que contribua para a emancipação humana e que prove "que o ser humano é maior do que os mecanismos que o minimizam [...]. A desconsideração total pela formação integral do ser humano e sua redução a puro treino fortalecem a maneira autoritária de falar de cima para baixo" (FREIRE, 2018, p. 113). Devemos, como professores comprometidos com a formação integral, recusar veementemente os "[...] determinismos que reduzem a nossa presença na realidade histórico-social à pura adaptação a ela" (FREIRE, 2018, p. 127).

Ainda remetendo ao pensamento de Freire (2018, p. 134-135), para que o ensino seja uma decisão ético-política de intervir no mundo, é papel do educador reconhecer e pautar sua atividade pedagógica na realidade e condições materiais em que vivem os educandos, condições essas que favorecem a compreensão do próprio mundo e de sua capacidade de aprender. Fazemos uma educação emancipatória ao diminuir a distância que separa as suas condições socioculturais de nossa prática docente e pedagógica, na medida em que ajudamos a aprender não importa que saber, o do torneiro mecânico ou do cirurgião, com vista à mudança do mundo, à superação das estruturas injustas. Sempre para sua mobilização e nunca para a conformação. 


\section{CONSIDERAÇÕES FINAIS}

Nosso caminho até aqui foi mostrar quão semelhante é a filosofia enquanto paideia com a pedagogia freiriana libertadora, o que coaduna a ideia da formação humana integral. Se analisarmos a Pedagogia do Oprimido, nela já nos deparamos com a ideia de integração e interdisciplinaridade, presente nos ideários atuais de formação educacional, uma vez que Freire já discutia sobre o campo educacional de forma holística, dialogando diretamente com filósofos, cientistas, psicólogos, militantes e trabalhadores, sem hierarquização ou verticalização do conhecimento. Para a aproximação da filosofia com a pedagogia freiriana, retomamos o logos (palavra), uma vez que é através da "palavra" que a filosofia se firma e tem seu auge na filosofia dialética socrática, em que o ensino da verdade se desenrola no diálogo. Para Freire (2018, p. 109), em sua filosofia da educação baseada na palavra, dizer a palavra não é privilégio de alguns homens, mas direito de homens e mulheres, que através do diálogo entre si e com o mundo se mediatizam e humanizam. Com a palavra (logos), o homem alcança sua "vocação ontológica" de tornar-se homem. Ao pronunciar sua palavra, assume conscientemente sua essência humana e revela o mundo que os homens construíram. Se ele foi construído, pode, necessariamente, ser reconstruído.

O diálogo em Freire é uma prática radical, que torna vívida a chama entre reflexão e ação. É através do diálogo que os seres humanos podem construir uma sociedade mais consciente e cultivar a esperança num futuro mais humanizador. Aliás, a educação em Freire é um movimento de exercitar a esperança pela mudança social, (re)examinando paradigmas que já não dão respostas a realidade concreta do campo educacional. A pedagogia freiriana é uma filosofia da utopia, mas também da práxis, onde os sujeitos históricos têm compromisso ético e político com a transformação da realidade, onde a humanização do mundo é idealizada pela ação cultural libertadora. Um projeto de educação humanista demanda que (re)examinemos a cultura, a educação, a ética, a política e a arte que cultivamos na era da informação e do mundo profissional, bem como os elementos intrínsecos a elas.

Nesse sentido, Freire faz uma filosofia da educação baseada na antropologia filosófica, ao entender, de forma consciente, os homens como seres em devir, que ao encontrarem sua subjetividade e problematização de suas realidades podem vir a ser, seres da transformação do mundo. Sendo assim, acreditamos que podemos definir a ação educativa de Freire como um ânimo para educar pela lógica da liberdade, da consciência e da autonomia, conceitos centrais aos maiores filósofos da história e de suas teorias educacionais, mas que, de alguma forma, perdemos no processo de pensar a educação numa perspectiva mercadológica. 
Corroborando com a tendência pedagógica que defendemos, o ensino de filosofia é uma ação que deve promover o diálogo, pressupondo as diferenças e diversidade dos seres. Sua finalidade é formativa do humano, principalmente para uma educação da empatia, da alteridade e da libertação.

Considerar um caráter dialógico para o ensino de filosofia é recusar o ensino como um desfile infindável de teorias e ideias fragmentadas, apartadas da realidade de um contexto histórico e cultural dos alunos. Se o professor de filosofia tomar a postura de superior aos alunos e entender a filosofia como um saber erudito e infalível, restrito a alguns indivíduos, essa prática nunca será dialógica, pois, só existe diálogo entre iguais.

Ao contrário, o sentido do ensinar filosofia está em tornar possível a sua prática como algo transformador dos seres e da realidade social. Ela é um diálogo e, por conseguinte, uma exigência existencial humana, não podendo ser reduzida a um ato de depositar ideias de um sujeito em outro, ele é, ao contrário, um instrumento de criação e recriação do mundo para promover a libertação de homens e mulheres.

O papel da filosofia na formação do aluno do ensino profissionalizante é de caráter epistemológico e político, a fim de fundamentar questões éticas, sociais e profissionais à luz de um saber que pode ser instrumento emancipatório. Vinte e sete séculos se passaram e a filosofia ainda fornece subsídios para a passagem de um pensamento dogmático para uma consciência mais crítica, que busca o sentido e a razão de ser das coisas e da própria existência. Então, ela pode subsidiar o aluno do ensino médio, ajudando-o a compreender o lugar que ele ocupa dentro de sua realidade histórica. Logo, o papel do ensino de filosofia não é só mostrar historicamente como as ideias foram forjadas, mas como elas foram criadas e como esses conceitos se impregnam no tecido social e político, problematizando sua criação e possibilitando sua recriação e ressignificação. A tarefa da educação filosófica é, portanto, mostrar a existência como liberdade e não como determinismo, seguindo a filosofia da educação freiriana.

\section{REFERÊNCIAS}

ARISTÓTELES. Política. Trad. Carlos Alberto Nunes. Brasília: Editora Universidade de Brasília, 1997.

ARISTÓTELES. Metafísica I. São Paulo: Abril Cultural, 1982.

ASPIS, R. Ensinar Filosofia: um livro para professores. São Paulo: Atta Mídia e educação, 2014. 
BRASIL. Ministério da Educação. Secretaria de Educação Profissional e Tecnológica. Câmara de Educação Básica. Educação Profissional técnica de nível médio integrada ao ensino médio. Brasília: MEC/CNE/CEB, 2007.

BRASIL. Lei no 11.892, de 29 de dezembro de 2008. Institui a Rede Federal de Educação Profissional, Cientifica e Tecnológica, cria os Institutos Federais. Diário oficial da União. Brasília, 30 dez.2008, Seção 1, p.1.

CALVINO, I. Por que ler os clássicos. São Paulo: Companhia das Letras, 2007.

CERLETTI, A. O ensino de filosofia como problema filosófico. Belo Horizonte: Autêntica, 2009.

CIAVATTA, M. A formação integrada: a escola e o trabalho como lugares de memória e identidade. In: Ensino Médio integrado: Concepções e Contradições. FRIGOTTO; CIAVATTA, M; RAMOS, M. (Orgs.) São Paulo: Cortez, 2005.

CIAVATTA, M. Ensino Integrado, a Politecnia e a Educação Omnilateral: por que lutamos? Revista Trabalho \& Educação, v. 23, n. 1, p. 187-205, 2016.

DELEUZE, G. Nietzsche e a filosofia. Rio de Janeiro: Editora Rio, 1976. DELEUZE, G.; GUATTARI, F. O que é a filosofia? Rio de Janeiro: Editora 34, 2016.

DELEUZE, G. Conversações. São Paulo: Editora 34, 2017.

DUMAS, A. O Conde de Monte Cristo. São Paulo: Zahar, 2014.

FREIRE, P. Extensão ou Comunicação? São Paulo: Paz e Terra, 1985.

FREIRE, P. Pedagogia do oprimido. Rio de Janeiro: Paz e Terra, 2018.

FREIRE, P. Pedagogia da autonomia: saberes necessários à prática educativa. Rio de Janeiro: Paz e Terra, 2019.

FRIGOTTO, G. Concepções e mudanças no mundo do trabalho e o ensino médio. In: Ensino Médio integrado: Concepções e contradições.

FRIGOTTO, Gaudêncio; CIAVATTA, Maria; RAMOS, Marise. (Orgs.) São Paulo: Cortez, 2005.

FRIGOTTO, G; RAMOS, M; CIAVATTA, M. A educação de trabalhadores no Brasil contemporâneo: um direito que não se completa. Germinal: Marxismo e Educação em Debate, Salvador, v. 6, n. 2, p. 65-76, dez. 2014.

GADOTTI, M. Uma só escola para todos: Caminhos da autonomia escolar. Petrópolis: Vozes, 1991.

GALLO, S. Metodologia de filosofia no ensino médio. São Paulo: Zahar, 2012.

GILES, T. Filosofia da Educação. 4. ed. São Paulo: E.P.U. 2007.

GHIRALDELLI Jr. P. Filosofia da Educação. Rio de Janeiro: DP\&A, 2000. 
GRAMSCI, A. Cadernos do cárcere. Rio de Janeiro: Civilização Brasileira, 1976

GRAMSCI, A. Concepção dialética da história. Rio de Janeiro: Civilização Brasileira, 1986.

JAEGER, W. W. Paideia: A Formação do Homem Grego. São Paulo: Martins Fontes, 1995.

KOSIK, K. A dialética do Concreto. Rio de Janeiro: Paz e Terra, 2002.

LACE, J. Curso de Filosofia grega. São Paulo: Zahar, 1994.

MINAYO, M.C.S. Hermenêutica-Dialética como caminho do pensamento social. In: M. S. S. MINAYO, MCS; DESLANDES, S. (Orgs.). Caminhos do

Pensamento - Epistemologia e Método. Rio de Janeiro: Fiocruz, 2010.

MIZUKAMI, M. Ensino: as abordagens do processo. São Paulo: EPU, 2001.

PACHECO, E. Os institutos federais: uma revolução na educação profissional e tecnológica. Natal: IFRN, 2010.

PACHECO, E. Institutos federais: uma revolução profissional e tecnológica. São Paulo: Moderna, 2011.

RAMOS, M. Possibilidades e desafios na organização do currículo integrado. In: FRIGOTTO, Gaudêncio; CIAVATTA, Maria; RAMOS, Marise. (Orgs.).

Ensino Médio integrado: Concepções e contradições. São Paulo: Cortez, 2005.

RAMOS, M. Currículo Integrado. In: PEREIRA, I; LIMA, J. (Org.). Dicionário de Educação da Educação Profissional em Saúde. Rio de Janeiro: EPSJV/Fiocruz, 2009. Disponível em:

http://www.sites.epsjv.fiocruz.br/dicionario/verbetes/curint.html.

RAMOS, M. História e política da educação profissional. Curitiba: InstitutoFederal do Paraná, 2016.

RODRIGO, L. Uma alternativa para o ensino de filosofia no nível médio. In: SILVEIRA, R. \& GOTO, R. (orgs.). Filosofia no ensino médio. São Paulo: Loyola, 2007.

SAVIANI, D. Pedagogia histórico-crítica: primeiras aproximações. 9.ed. Campinas: Autores Associados, 2011.

SAVIANI, D. A contribuição da filosofia para a educação. São Paulo: Aberto, 1990.

SAVIANI, D. Escola e democracia: teorias da educação, curvatura da vara, onze teses sobre educação e política. Campinas: Autores Associados, 1999.

SAVIANI, D. Pedagogia no Brasil: história e teoria. Campinas: Autores Associados, 2008.

SAVIANI, D. Educação do senso comum a consciência filosófica.

Campinas: Autores Associados, 2013. 
SAVIANI, D; DUARTE, N. A pedagogia histórico-crítica e aluta de classe na educação escolar. Campinas: Autores Associados, 2015.

SEVERINO, A.J. A contribuição da filosofia para a educação. Em aberto, ano 9, n 45, 1990.

SEVERINO, A.J. Desafios atuais do ensino de Filosofia. In: TRENTIN, R\&GOTO, R. (orgs.). Filosofia e seu ensino. São Paulo: Loyola, 2007.

SILVA, S. R. A civilização contra a tradição no projeto iluminista de Condorcet.Filosofia da Educação, n. 17, 2007. Disponível em:http://www.anped.org.br/sites/default/files/gt17-3001-int.pdf. Acesso em 30 de maio de 2019.

SILVA, S. R. Direitos humanos e instrução pública segundo Condorcet.

Educação em Revista, Marília, v.11, n.1, p.1-18, 2014.

SIMON, E. et al. Metodologias ativas de ensino-aprendizagem e educação popular: encontros e desencontros no contexto da formação dos profissionais de saúde. Interface, Comunicação, Saúde, Educação, v. 18, p. 1355-1364, 2014. 